\title{
THE NATIONAL FOOD SURVEY OF GREAT BRITAIN
}

\author{
Chairman: DR N. C. WRIGHT, Chief Scientific Adviser, Ministry of Food, \\ London, S.W.r
}

\section{Chairman's Opening Remarks}

By N. C. WRIGHT, Scientific Adviser's Division, Ministry of Food, Dean Bradley House, Horseferry Road, London, S.W.I

It is just ro years since the Society devoted two full meetings to the subject of budgetary and dietary surveys. In the intervening period a further full meeting has been held in Dublin for the purpose of discussing the Irish National Nutrition Survey. But this is the first occasion on which it has been possible to present to the Society a connected series of papers covering various aspects of the National Food Survey of Great Britain, an opportunity which my colleagues and I have very much welcomed.

It would perhaps be appropriate in these introductory remarks to refer briefly to the purpose for which the survey was begun and to the changes in objective and coverage which have taken place since its commencement in 1940. The survey was not designed to provide information that would enhance scientific knowledge in its narrower sense. It was initiated, in the climate of the thirties, against a background of the poorer diets which prewar surveys had demonstrated in certain sections of the British population; and it was planned to provide administrators with early warnings of any dietary inadequacy that might result from wartime shortages and changes in dietary pattern, particularly among those who were thought to be nutritionally most vulnerable. In these circumstances it was assumed that the effectiveness of the wartime food policy would be most clearly reflected in the food consumption and expenditure of urban working-class households.

With the termination of the war and the end of the immediate postwar shortages it became clear that, if the survey was to provide a basis for guidance on food policy that would take into account the changing circumstances of different groups of the population, its scope would need to be widened. Accordingly in $195^{\circ}$ the coverage was increased in such a way as to furnish records for a complete cross-section of the population, and thus to facilitate the pin-pointing of any groups whose diet appeared to need attention.

During and immediately after the war it was not possible to analyse, in a form suitable for publication, the great mass of information that had been collected. 
But in 1948 a National Food Survey Committee was appointed by the Ministry of Food and was invited to consider the available material and to advise as to the best means of making it available both to the public at large and to those-such as members of this Society-to whom it would be of professional interest. The first report of the Committee was issued in 195I, and covered - largely in terms of national averages-the food consumption and expenditure for the years from 1940 to 1949 (Ministry of Food: National Food Survey Committee, 1951). I might mention that a second report, containing a number of papers dealing with certain specific aspects of the earlier data, is at present in course of preparation.

At the same time the Committee felt that it was essential, if better use was to be made of succeeding data, to arrange for the periodic issue of a series of annual reports. The first of these-that for 1950-coincided with the commencement of the enlarged coverage; since then two further annual reports-those for $195^{\text {I }}$ and $195^{2-}$ have been issued, the latter as recently as 2 days ago (Ministry of Food: National Food Survey Committee, 1953, 1954). I would add that it is the Committee's objective to arrange for the issue of future annual reports rather more promptly than has been possible in the past; but it will be appreciated that, with the large backlog of unpublished data, it has not been easy to make up leeway rapidly.

In planning the programme for this symposium my colleagues and I felt that we should present material not readily accessible in the Committee's official reports. These reports provide annual comparisons of food consumption and expenditure and of the nutritive value of the diet, both for a complete national sample and for groups classified according to social class and family composition. They also provide information on such subjects as seasonal variations in food consumption and expenditure. In to-day's symposium those who are contributing papers have gone beyond such routine analyses and are presenting information on a variety of aspects of the national diet (and of the survey itself), which is either not available in the reports or is presented with a different emphasis or a different background. It was hoped by this means to indicate the manifold purposes for which the survey data can be used, as well as the value of the results already obtained.

The first paper (Readman, I955) deals with the technique of the survey. This subject has already been covered in some detail in the appendices to the published reports, but it was felt that members of the Society might wish to be reminded of the methods adopted in selecting the survey samples, in the collection of records from housewives, and in the analyses and interpretation of the results. Mr. Readman's paper, in addition, brings up to date the published accounts of methodology. At a recent meeting of the Society reference was made (Woolf, 1954) to the response rate achieved in the survey and to the problems of sampling when estimates are needed for subgroups of the population. Mr Readman gives a description of the methods adopted to increase the representative character of the sample and of the improvements achieved in response rate.

The second paper (Brown, I955) is designed to demonstrate one of the statistical uses to which the National Food Survey records can be put. The recently published annual report for $195^{2}$ (Ministry of Food: National Food Survey Committee, 1954) 
contains a section on the relation of number of children to food expenditure which includes the following sentence: 'To establish true equivalent-adult scales, which give the cost of a child compared with the cost of an adult at the same standard of living, the effect of family income per head would have to be taken into account'. $\mathrm{Mr}$ Brown's paper on economics, nutrition and family food budgets is intended to provide an elaboration of this theme. The fifth paper (Gibson, Readman \& Warnock, 1955) is also a development of the same theme, in which the technique already applied to food expenditure is extended to food consumption, nutrient intake and nutrient requirements.

In the third paper Miss Hollingsworth (1955) considers some aspects of the pattern of the national diet just before the end of 14 years of rationing. The subject is complex and the position is too fluid to warrant conclusions as to patterns that may develop when the population has had time to settle down to purchasing habits no longer influenced by the ration book. The patterns of expenditure and nutritional distribution of the diet were strikingly different in 1952 compared with those before the war, though some commodities were still subject to the restraints of control. Four food groups of nutritional importance which were not rationed in $195^{2}$ are, however, separately discussed as an indication of what might be permanent patterns.

The problem of ageing is one of great topical interest, which clearly merited special study. Although in general the National Food Survey is designed to assess the food consumption and expenditure of families and not of individuals, the survey samples do include records for individual old-age pensioners and other elderly people living alone. In the fourth paper (Baines \& Hollingsworth, 1955) such records are analysed and discussed. The results are not only of value as an indication of the diets of the ageing population, but may well be of significance in the much debated subject of the relation of increasing age to energy and nutrient requirements.

In the final paper of the series Leitch (1955) who-with a unique background of experience in prewar surveys and as a member of the National Food Survey Committee-is in a special position to assess the value of the survey results, reviews their significance and relates the more important findings to those of the prewar Carnegie data.

May I again stress the fact that one of our main objects in presenting this series of papers to the Society has been to indicate the wealth of material available for analyses other than those needed for the annual reports. I know that my colleagues who are responsible for the National Food Survey will not only welcome comments and criticisms to-day but-within the resources available-would equally welcome the active co-operation of any members of the Society who, for research purposes, may be in a position to suggest and undertake new and promising lines of inquiry.

\section{REFERENCES}

Baines, A. J. H. \& Hollingsworth, D. F. (1955). Proc, Nutr. Soc. 14, 77.

Brown, J. A. C. (1955). Proc. Nutr. Soc. 14, 63.

Gibson, E. H., Readman, W. L. \& Warnock, G. M. (1955). Proc. Nutr. Soc. 14, 80.

Hollingsworth, D. F. (1955). Proc. Nutr. Soc. 14, 7 I.

Leitch, I. (1955). Proc. Nutr. Soc. 14, 86. 
Ministry of Food: National Food Survey Committee (195 r). The Urban Working-class Household Diet 1940 to 1949. London: H.M. Stationery Office.

Ministry of Food: National Food Survey Committee (1953). Domestic Food Consumption and Expenditure, 195I. London: H.M. Stationery Office.

Ministry of Food: National Food Survey Committee (1954). Domestic Food Consumption and Expenditure, 1952. London: H.M. Stationery Office.

Readman, W. L. (1955). Proc. Nutr. Soc. 14, 60.

Woolf, B. (1953). Proc. Nutr. Soc. 13, 82.

\section{Technique and Methods of the National Food Survey}

By W. L. Readman, Statistics and Intelligence Division, Ministry of Food, 12-I 4

\section{Sussex Place, London, N.W.I}

The annual reports of the National Food Survey (Ministry of Food: National Food Survey Committee, 1952, 1953, 1954) describe in detail changes in techniques up to 1952. During February and March 1953 the Social Survey Division of the Central Office of Information took over the sampling, field work, coding, punching and regular monthly tabulations. The sampling is based on a rigorous three-stage sample design, of which full details will be given in the 1953 annual report. The use of the 'juror index' (Corlett, 1952) in England and Wales helped to secure the correct proportions of areas of different economic status. The methods of selection of addresses from the Electoral Register at the final stage and the instructions given to interviewers regarding the use of these samples follow the Social Survey's standard practice described elsewhere (Gray, Corlett \& Frankland, 1950).

During the year, addresses are selected from ro80 polling districts in the sixty parliamentary constituencies which form the first-stage sampling units. Interviews are made in half the constituencies alternately for periods of 3 weeks, during which two polling districts within each of these constituencies are sampled for Io days each. The number of addresses to be approached by each interviewer during the first 3 days of each ro has been reduced to 20 , enabling further recalls to be made on the more elusive housewives. The Social Survey's normal practice of requiring the interviewers to work in the evening when necessary has been introduced. As a result of these changes the response rates are now higher than in previous years. During the second half of 1953 , completed log-books were received from $56 \%$ of the addresses visited, compared with $43 \%$ in January-August 1952. In 1952, however, not all the chosen addresses were visited. Of addresses selected, the percentage was 37.

The tendency of the Survey sample to include an undue proportion of children has been reduced. In 1950 , when national coverage was first attempted, children aged o-9 formed $22.5 \%$ of the sample. In the 18 months following the simplification of the log-book in June I95 I the percentage was 19.8. Since April r953 it has averaged 18.9. The true figure for the household population which the Survey aims to cover cannot be exactly determined from official sources. A value of $17 \%$ may be derived from the I95 I census for all private households (Registrar-General, 